\title{
Outcome of HIV-exposed uninfected children undergoing surgery
}

Jonathan S Karpelowsky ${ }^{1 *}$, Alastair JW Millar ${ }^{1+}$, Nelleke van der Graaf ${ }^{2+}$, Guido van Bogerijen ${ }^{2+}$ and Heather J $\operatorname{Zar}^{3+}$

\begin{abstract}
Background: HIV-exposed uninfected (HIVe) children are a rapidly growing population that may be at an increased risk of illness compared to HIV-unexposed children (HIVn). The aim of this study was to investigate the morbidity and mortality of HIVe compared to both HIVn and HIV-infected (HIVi) children after a general surgical procedure.

Methods: A prospective study of children less than 60 months of age undergoing general surgery at a paediatric referral hospital from July 2004 to July 2008 inclusive. Children underwent age-definitive HIV testing and were followed up post operatively for the development of complications, length of stay and mortality.

Results: Three hundred and eighty children were enrolled; 4 died and 11 were lost to follow up prior to HIV testing, thus 365 children were included. Of these, 38(10.4\%) were HIVe, 245(67.1\%) were HIVn and 82(22.5\%) were HIVi children.

The overall mortality was low, with 2(5.2\%) deaths in the HIVe group, 0 in the HIVn group and 6(7.3\%) in the HIVi group ( $p=0.0003$ ). HIVe had a longer stay than HIVn children (3 (2-7) vs. $2(1-4)$ days $p=0.02)$. There was no significant difference in length of stay between the HIVe and HIVi groups. HIVe children had a higher rate of complications compared to HIVn children, (9 (23.7\%) vs. 14(5.7\%) (RR 3.8(2.1-7) p < 0.0001) but a similar rate of complications compared to HIVi children 34 (41.5\%) $(\mathrm{RR}=0.6(0.3-1.1) \mathrm{p}=0.06)$.

Conclusion: HIVe children have a higher risk of developing complications and mortality after surgery compared to HIVn children. However, the risk of complications is lower than that of HIVi children.
\end{abstract}

\section{Background}

HIV-exposed uninfected (HIVe) children are a rapidly growing population. Programs for the prevention of mother to child transmission (PMTCT) have reduced the transmission rate of perinatal HIV infection to approximately $2 \%$ to $5 \%$ [1-3]. Such programs have therefore effectively reduced the number of HIV infected (HIVi)children but identified an increasing population of HIVe children [4].

HIVe children have been overlooked as a group of children who may be at an increased risk of illness compared to HIV-unexposed (HIVn) children. Recently, increased morbidity and mortality in HIVe children

\footnotetext{
* Correspondence: jonathk2@chw.edu.au

+ Contributed equally

'Department of Pediatric Surgery, Red Cross War Memorial Children's Hospital, School of Child and Adolescent Health, University of Cape Town, South Africa

Full list of author information is available at the end of the article
}

compared to HIVn children has been reported [4-10]. Many factors may account for this including innate deficiencies in immunity [11-13], feeding practices [14], poor protection from maternal antibodies or environmental exposures [6].

As PMTCT programs expand, an increasing number of HIVe children can be expected to require a routine or emergency surgical procedure $[15,16]$. Currently no data exist on the risk of morbidity and mortality postsurgery in such children. The aim of this study was to investigate the mortality and post-operative complications in HIVe children compared to both HIVn and HIVi children after a general surgical procedure.

\section{Methods}

A prospective cohort study was performed, from July 2004 to July 2008 at a single tertiary general paediatric surgical centre in Cape Town, Western Cape, South Africa. The general paediatric surgical service acts as a

\section{Ciomed Central}


regional and national referral centre with approximately 2400 operations performed annually. The study was approved by the ethics committee of the Faculty of Health sciences, University of Cape Town.

The study site is a high HIV prevalence area, with an estimated HIV prevalence amongst pregnant women of approximately $16 \%$ [17]. There is a well-developed PMTCT program with HIV transmission rates of approximately $2-4 \%$. The Western Cape has approximately 70000 births per annum [1], of which approximately 11000 babies per year are expected to be HIVe.

Inclusion criteria were children less than 60 months of age, undergoing a general surgical procedure. The recruitment was conducted in two phases. 1) Phase 1 (pilot data), enrolled only HIV-exposed children, from July 2004 to December 2006. This was done to gather pilot data, to inform the larger phase 2 study. 2) Phase 2 enrolled all children irrespective of HIV exposure from January 2007 until July 2008 inclusive. Analysis was conducted on both phase 1 and phase 2 data.

Age definitive HIV testing with pre and post-test counselling was done in children whose HIV status was unknown. HIV infection was defined as 2 positive HIV ELISA (Determine ${ }^{\circledR}$ Abbott, Abbott Park, Ill. USA) tests in children > 18 months; a positive ELISA test, and if positive a confirmatory PCR test in children less than 18 months. HIV exposure was defined as a positive ELISA but negative PCR in children $<18$ months or in children $>18$ months knowledge of an infected mother but a negative ELISA in the child.

Informed consent from a parent or legal guardian was obtained. Details of the child's demographics, clinical examination, medication, haematological tests, HIV status and treatment, surgery and complications were recorded until discharge, death or in the case of prolonged admissions 60 days following their last surgical procedure or surgical complication.

Children formed 3 groups- 1 . HIV-exposed (HIVe) but uninfected 2.HIV unexposed (HIVn), 3. HIV infected (HIVi). HIVe children were compared to the HIVn and the HIVi groups

A procedure entailed a general surgical operation under general anaesthetic. Surgical procedures were defined as emergency (which in the opinion of the treating clinician unless performed in 24 hours of hours of admission would result in either morbidity or mortality of the child) or elective. Procedures were also defined as major (which entailed entry into a body cavity (abdomen or thorax), oncological resection, and a prolonged procedure longer than 90 min or vascular reconstruction) or minor. A contaminated case was defined as pus, infection, or gross contamination present at the site of surgery when performing the procedure. Prophylactic antibiotics were used in major cases or contaminated cases according to local microbiological guidelines. This included a cephalosporin and metronidazole or alternatively, penicillin an aminoglycoside and metronidazole, depending on the procedure.

The primary outcome was the occurrence of a complication, defined as an adverse event occurring in the intra, or post-operative period which is not expected to occur either during or following the normal course of the procedure. Secondary outcomes were length of stay (calculated in days from the day of admission until the day of discharge or death) and mortality.

\section{Statistical analysis}

Descriptive data is presented as means +/- standard deviation, medians with an interquartile range (IQR) or proportions with a $95 \%$ confidence interval. Normality of data was tested using the Shapiro-Wilks test. Hypothesis testing, using either the chi squared or fisher exact test for dichotomous or ordinal variables was done. The student t-test was used for the comparison of means and the Wilcoxon rank-sum test for comparing medians of continuous variables. Nutrition assessed using weight for height $\mathrm{Z}$ scores as a continuous variable and a dichotomous variable with a weight for age Z-Score of less than -2 being malnourished. Relative risks were calculated for complications or mortality. Following the initial comparisons, age adjusted control groups were formed in the HIVn and HIVi groups due to the significantly younger age of the HIVe children. This was done by selecting appropriate matched controls within one month of age for each HIVe case. Due to the sample size, 3 age matched controls could be selected from the HIVn group, and a single age matched control from the HIVi group. Furthermore age as a confounding variable was tested on multivariate analysis in three different models, the entire cohort, HIVe and HIVn children and HIVe and HIVi children. The regression models were constructed for complications. This was done by including factors significant on univariate analysis or alternatively of strong clinical importance as a backward step regression until the best fit was obtained. Data was analysed using Stata (Version10.0, College Station, Tx USA). Significance was set at $\mathrm{p}<0.05$ and results were expressed as proportions and relative risk with $95 \%$ confidence intervals.

\section{Results}

Three hundred and eighty children were enrolled (94 during, phase 1); 4 died and 11 were lost to follow up prior to PCR testing, thus 365 children were included. Of these, 38(10.4\%) were HIVe, 245(67.1\%) were HIVn and $82(22.5 \%)$ were HIVi children.

The median age of children was 11 (IQR 4.4-26.6) months. HIVe children were younger, 4.5 (IQR 0.8-11.2) 
Table 1 Comparison of HIV exposed uninfected and HIV unexposed children

\begin{tabular}{|c|c|c|c|c|}
\hline & $\mathrm{HIVe}(\mathrm{n}=38)$ & $\mathrm{HIVn}(\mathrm{n}=245)$ & Relative Risk & Significance \\
\hline Age(months) & $4.5(0.8-11.2)$ & $12.7(4.4-29.4)$ & & $p<0.00001^{*}$ \\
\hline \multicolumn{5}{|l|}{ Nutrition } \\
\hline - Z-score weight for age & $-1.74(-3.4--0.5)$ & $-0.63(-1.7-0.18)$ & & $P=0.0002^{*}$ \\
\hline - Malnutrition (Z-score<-2) & $18(47.4 \%)$ & $43(17.5 \%)$ & $\mathrm{RR}=2.7(1.8-4.2)$ & $p<0.00001^{*}$ \\
\hline Major cases & $17(44.7 \%)$ & $64(26.1 \%)$ & $\mathrm{RR}=1.7(1.2-2.6)$ & $P=0.01^{*}$ \\
\hline Contaminated cases & $15(39.4 \%)$ & $49(20 \%)$ & $\mathrm{RR}=2(1.3-3.1)$ & $P=0.008^{*}$ \\
\hline Emergency cases & $12(31.5 \%)$ & $95(38.8 \%)$ & & $P=0.8$ \\
\hline No. of patients with a Complication & $9(23.7 \%)$ & $14(5.7 \%)$ & $\mathrm{RR}=4.2(1.9-8.9)$ & $p<0-.0001^{*}$ \\
\hline Mortality & $2(5.2 \%)$ & $0(0 \%)$ & & $P=0.0003^{*}$ \\
\hline Length of stay (days) & $3-(2-7)$ & $2(1-4)$ & & $P=0.02^{*}$ \\
\hline
\end{tabular}

Values expressed as medians (interquartile range) for continuous and number (percentage) for dichotomous variables. Relative risk is expressed as the RR (95\% confidence interval) * are significant values.

months than the HIVi (11.5 months (IQR 6-24) p < $0.0001)$ or HIVn (12.7 months (IQR 4.4-29.4) p = < $0.0001)$ children. HIVe children had a higher number of major procedures, contamination at the surgical site and worse nutrition compared to HIVn children (table 1). Following age matching of HIVe and HIVn children, an increased surgical site contamination and worse nutrition persisted in HIVe children (table 2). HIVe and HIVi children were well matched for the level of procedure, surgical site contamination, urgency, nutrition and number of urgent procedures in both the age matched and unmatched groups (table 3,4 )

The overall mortality ( 8 deaths, $2.2 \%$ ) was low, with 2 (5.2\%) deaths in the HIVe group, none in the HIVn group and $6(7.3 \%)$ in the HIVi group. The mortality rate was significantly higher in HIVe compared to HIVn children $(\mathrm{p}=0.0003)$. This difference persisted when matching for age $\mathrm{p}=0.01$ (table 2). No significant difference in mortality was demonstrated between HIVe and HIVi children (table 3, 4).

HIVe had a longer duration of hospitalisation than HIVn children $(3(2-7)$ vs. $2(1-4)$ days $\mathrm{p}=0.02)$, but this difference did not persist with age matching of the groups ((3 (2-7) vs. $2(1-5)$ days $\mathrm{p}=0.2)$. There was no significant difference in length of stay between the HIVe and HIVi groups.

Overall 57 (15.6\%) children developed a complication. The HIVe children had a higher rate of complications, compared to HIVn children [9 (23.7\%) vs. 14.5.7\%) (RR 4.18(1.9-8.9) $\mathrm{p}<0.0001$ )] (table 1 ), but a similar rate compared to HIVi children [9(23.7\%) vs. 34 (41.5\%) (RR $=0.6(0.3-1.1) \mathrm{p}=0.06)]$ (table 3). Using aged matched controls there was still a significant difference in the rate of complications between HIVe and HIVn children [9 (23.7\%) vs. 10 (8.7\%) (RR $2.3(1.3-4.1) \mathrm{p}=0.008)$ ] (table 2). After age matching, HIVe children had a lower risk of complications than HIVi children $[(9(23.7 \%)$ vs. 24. (63.2\%)(RR 0.4 (0.2-0.7) $\mathrm{p}=0.0005)$ ] (table 4)

A total of 71 complications occurred in 57 children (table 5). The commonest complications were surgical site complications in $34 / 71$ (48\%). Of these $13 / 34(38 \%)$ were wound infection, 7/34(20.5\%) were wound breakdown (without clinical or microbiological infection), $7 /$ $34(20.5 \%)$ involved breakdown of an enteric stoma, 4/34 (11\%) were early recurrence of the surgically treated condition and 3/34(9\%) were anastomotic obstruction or

Table 2 Comparison HIV exposed uninfected children and age matched HIV unexposed children

\begin{tabular}{|c|c|c|c|c|}
\hline & $\mathrm{HIVe}(\mathrm{n}=38)$ & Age matched HIVn(n = 114) & Relative Risk & Significance \\
\hline Age(months) & $4.5(0.8-11.2)$ & $4.4(1.8-11)$ & & $p=0.6$ \\
\hline \multicolumn{5}{|l|}{ Nutrition } \\
\hline - Z-score weight for age & $-1.74(-3.4--0.5)$ & $-0.86(-1.8-0)$ & & $P=0.01^{*}$ \\
\hline - Malnutrition (Z-score<-2) & $18(47.4 \%)$ & $26(22.8 \%)$ & $\mathrm{RR}=2(1.3-3.3)$ & $p=0.004^{*}$ \\
\hline Major cases & $17(44.7 \%)$ & $34(29.8 \%)$ & & $p=0.09$ \\
\hline Contaminated cases & $15(39.4 \%)$ & $20(17.5 \%)$ & $\mathrm{RR}=2.1(1.3-3.7)$ & $p=0.01^{*}$ \\
\hline Emergency cases & $12(31.5 \%)$ & $51(44.7 \%)$ & & $p=0.2$ \\
\hline No. of patients with a Complication & $9(23.7 \%)$ & $10(8.7 \%)$ & $\mathrm{RR}=2.3(1.3-4.1)$ & $p=0.008^{*}$ \\
\hline Mortality & $2(5.2 \%)$ & $0(0)$ & & $p=0.01^{*}$ \\
\hline Length of stay (days) & $3-(2-7)$ & $2(1-5)$ & & $P=0.2$ \\
\hline
\end{tabular}

Values expressed as medians (interquartile range) for continuous and number (percentage) for dichotomous variables. Relative risk is expressed as the RR ( $95 \%$ confidence interval) * are significant values. 
Table 3 Comparison of HIV exposed uninfected and HIV infected children

\begin{tabular}{llll}
\hline & HIVe$(\mathbf{n}=\mathbf{3 8})$ & HIVi(n= 82) & Significance \\
\hline $\begin{array}{l}\text { Age(months) } \\
\text { Nutrition }\end{array}$ & $4.5(0.8-11.2)$ & $11.5(6-24)$ & $\mathrm{P}<0.0001^{*}$ \\
$\cdot$ - Z-score weight for age & $-1.74(-3.4--0.5)$ & $-2.0(-3.4--0.97)$ & $\mathrm{P}=0.7$ \\
- Malnutrition (Z-score<-2) & $18(47.4 \%)$ & $41(50.0 \%)$ & $\mathrm{P}=0.8$ \\
Major cases & $17(44.7 \%)$ & $28(34.2 \%)$ & $\mathrm{P}=0.1$ \\
Contaminated cases & $15(39.4 \%)$ & $40(48.7 \%)$ & $\mathrm{P}=0.2$ \\
Emergency cases & $12(31.5 \%)$ & $37(45.1 \%)$ & $\mathrm{P}=0.8$ \\
No. of patients with a Complication & $9(23.7 \%)$ & $34(41.5 \%)$ & $\mathrm{P}=0.06$ \\
Mortality & $2(5.2 \%)$ & $6(7.3 \%)$ & $\mathrm{P}=0.8$ \\
Length of stay (days) & $3-(2-7)$ & $4(2-14)$ & $\mathrm{P}=0.5$ \\
\hline
\end{tabular}

Values expressed as medians (interquartile range) for continuous and number (percentage) for dichotomous variables. Relative risk is expressed as the RR (95\% confidence interval) * are significant values.

stenosis. The second commonest complication was postoperative systemic infection, comprising pneumonia in $10 / 31(32 \%)$, sepsis with bacteraemia in $13 / 31(42 \%)$, central line sepsis $5 / 31(16 \%)$ and one case each of cholangitis, urinary infection and intra-abdominal sepsis $3 / 31$ (10\%). Other complications occurring in $6 / 71(8 \%)$ included postoperative airway obstruction due to vocal cord palsy, dehydration and hypoglycaemia. Of the complications recorded, HIVe children had a higher proportion of systemic post-operative infections than both HIVn children $[12 / 16(75 \%)$ vs. $8 / 18(44 \%) \mathrm{p}=0.05 \mathrm{RR}$ $1.7(1.1-3)]$ and HIVi children [12/16(75\%) vs. $11 / 37$ $(30 \%) \mathrm{p}=0.002 \mathrm{RR}=2.5(1.4-4.5)]$

Logistic regression comparing HIVe and HIVn children and HIVe and HIVi children included significant variables on univariate analysis, and other clinically important variables such as nutrition, urgency of surgery and surgical site contamination. Following backward step regression for HIVe and HIVn children it was demonstrated that HIV exposure and undergoing a major procedure were the most predictive of developing a complication (table 6). Models for HIVe and HIVi children demonstrated that HIV status, age under 12 months and undergoing a major procedure were the most predictive of developing a complication (table 7).

\section{Discussion}

This study has shown that HIVe children undergoing surgery have an intermediate risk of complications postsurgery; higher than that of HIVn children, but lower than HIV infected HIVi children. In addition, in hospital mortality post-surgery was higher in HIVe children compared to that in HIVn children.

The increased morbidity and mortality related to HIV exposure may be due to many factors. HIVe children may have poorer growth and nutrition, increased risk of infection, impaired passive immunity from maternal antibodies, or greater exposure to potential pathogens in a household with a HIV infected adult.

HIVe children had worse nutrition compared to those who were HIVn. Reasons for poorer nutrition may include parental illness and poverty $[18,19]$, infant feeding practices $[14,18]$, lack of breast feeding, and an increase disease burden in exposed children $[6,13,14,19]$. Although breast feeding rates were not recorded, it is likely that there would have been a low breast feeding

Table 4 Comparison HIV exposed uninfected and age matched HIV infected children

\begin{tabular}{|c|c|c|c|c|}
\hline & $\mathrm{HIVe}(\mathrm{n}=38)$ & Age matched HIVi $(n=38)$ & Relative Risk & Significance \\
\hline Age(months) & $4.5(0.8-11.2)$ & $6(4.4-10)$ & & $p=0.4$ \\
\hline \multicolumn{5}{|l|}{ Nutrition } \\
\hline - Z-score weight for age & $-1.74(-3.4--0.5)$ & $-1.9(+/-1.7)$ & & $P=0.9$ \\
\hline - Malnutrition (Z-score<-2) & $18(47.4 \%)$ & 19 (50\%) & & $P=0.8$ \\
\hline Major cases & $17(44.7 \%)$ & $16(42.1 \%)$ & & $P=0.8$ \\
\hline Contaminated cases & $15(39.4 \%)$ & $20(52.6 \%)$ & & $P=0.2$ \\
\hline Emergency cases & $12(31.5 \%)$ & $14(36.8 \%)$ & & $P=0.6$ \\
\hline No. of patients with a Complication & $9(23.7 \%)$ & $24(63.2 \%)$ & $\begin{array}{l}\mathrm{RR}=0.40 \\
(0.22-0.73)\end{array}$ & $P=0.0005^{*}$ \\
\hline Mortality & $2(5.2 \%)$ & $5(13.1 \%)$ & & $P=0.4$ \\
\hline Length of stay (days) & $3-(2-7)$ & $4(2-22)$ & & $P=0.2$ \\
\hline
\end{tabular}

Values expressed as medians (interquartile range) for continuous and number (percentage) for dichotomous variables. Relative risk is expressed as the RR (95\% confidence interval) * are significant values. 
Table 5 Comparison of post-operative complications in HIV infected, HIV unexposed and HIV exposed uninfected children

\begin{tabular}{|c|c|c|c|}
\hline \multirow[b]{2}{*}{ Total Complications (71) } & \multicolumn{3}{|c|}{ HIV Status } \\
\hline & HIVi (37) & $\begin{array}{c}\text { HIVn } \\
(18)\end{array}$ & $\begin{array}{l}\text { HIVe } \\
(16)\end{array}$ \\
\hline $\begin{array}{l}\text { Systemic Post-operative infection 31/ } \\
\underline{71(44 \%)}\end{array}$ & $\frac{11 / 37}{(30 \%)}$ & $\frac{8 / 18}{(44 \%)}$ & $\frac{12 / 16}{(75 \%)}$ \\
\hline Pneumonia & $\begin{array}{c}5 / 11 \\
(45.5 \%)\end{array}$ & $2 / 8(25 \%)$ & $\begin{array}{l}3 / 12 \\
(25 \%)\end{array}$ \\
\hline Bacteraemia & $\begin{array}{c}5 / 11 \\
(45.5 \%)\end{array}$ & $2 / 8(25 \%)$ & $\begin{array}{l}6 / 12 \\
(50 \%)\end{array}$ \\
\hline Central Line sepsis & 1/11(9\%) & $2 / 8(25 \%)$ & $\begin{array}{c}2 / 12 \\
(16.7 \%)\end{array}$ \\
\hline Urinary tract & 0 & $\begin{array}{c}1 / 8 \\
(12.5 \%)\end{array}$ & 0 \\
\hline Cholangitis & 0 & $\begin{array}{c}1 / 8 \\
(12.5 \%)\end{array}$ & 0 \\
\hline Intra-abdominal & 0 & 0 & $\begin{array}{l}1 / 12 \\
(8.3 \%)\end{array}$ \\
\hline$\underline{\text { Surgical site complication 34/71(48\%) }}$ & $\frac{24 / 37}{(65 \%)}$ & $\frac{6 / 18}{(33 \%)}$ & $\frac{4 / 16}{(25 \%)}$ \\
\hline Wound Infection & $8 / 24(33 \%)$ & $3 / 6(50 \%)$ & $2 / 4(50 \%)$ \\
\hline Wound break down & $7 / 24(29 \%)$ & 0 & 0 \\
\hline Stoma complication & $5 / 24(21 \%)$ & 1/6(17\%) & $1 / 4(25 \%)$ \\
\hline Recurrence & $4 / 24(17 \%)$ & 0 & 0 \\
\hline Anastomotic obstruction/stenosis & 0 & 2/6(33\%) & $1 / 4(25 \%)$ \\
\hline Miscellaneous 6/71 (8\%) & $2 / 37(5 \%)$ & $\begin{array}{l}4 / 18 \\
(22 \%)\end{array}$ & 0 \\
\hline
\end{tabular}

rates in keeping with the PMTCT policy, which was formula feeding of children born to HIV-infected mothers in the Western Cape Province at the time of the study. Several cohort studies have reported HIVe children to have worse nutrition compared to HIVn children [19].

HIVe children have been reported to have an increased risk of infection compared to HIVn children [4,6,10,19-23]. Infections in HIVe also tend to be more severe than in HIVn children $[6,10,19,24,25]$. Many of these infections are opportunistic infections occurring in an immune-compromised host $[4,10,19,24]$. There appears that in addition to environmental and feeding practices HIVe children have an impaired innate immunity $[5,19]$. This may increase susceptibility to infection and increase the risk for developing post-operative

Table 6 Logistic regression for complications with HIV exposed uninfected children and HIV unexposed children

\begin{tabular}{llll}
\hline Variable & $\begin{array}{l}\text { Odds } \\
\text { Ratio }\end{array}$ & Significance & $\begin{array}{l}\text { 95\% confidence } \\
\text { interval }\end{array}$ \\
\hline HIV exposure & 4.9 & $P=0.006$ & $1.6-15.4$ \\
Age & 0.9 & $P=0.09$ & $0.9-1.2$ \\
Major & 9.2 & $P<0.0001$ & $3.2-25.0$ \\
procedure & & & \\
\hline
\end{tabular}

Table 7 Logistic regression for complications with HIV exposed uninfected children and HIV infected children

\begin{tabular}{llll}
\hline Variable & $\begin{array}{l}\text { Odds } \\
\text { Ratio }\end{array}$ & Significance & $\begin{array}{l}\text { 95\% confidence } \\
\text { interval }\end{array}$ \\
\hline HIV exposure & 0.5 & $p=0.01$ & $0.3-0.8$ \\
Age under 12 & 5.2 & $p=0.001$ & $1.9-14.4$ \\
months & & & \\
Major procedure & 5.5 & $p<0.0001$ & $2.1-14.0$ \\
\hline
\end{tabular}

complications. This was consistent with our findings of a high rate of infections in HIVe children post operatively.

Major procedures are a clearly identified risk factor associated with an increased risk for the development of complications [26] and risk stratification to account for complications is well described $[27,28]$. Increased complexity of the procedure (thus increasing the risk of technical problems), immune dysregulation related to the stress response to surgery or impaired respiratory function in the post-operative period may all contribute to this [29].

There are several limitations to this study. The relatively lower age of the HIVe compared with HIVi and HIVn patients may have been a confounding variable as the HIVe children may not have had a fully developed immune system. We have attempted to account for this in multivariate analysis and secondly by age matching to HIVi and HIVn children. In both instances when age was accounted for, HIV status had an important effect on post-operative outcomes with HIVe children having a risk in between that of HIVn and HIVi children. This study has a small number of HIVe children which may have influenced the results and larger studies are needed with stratification of the HIVe group based on age of the child, feeding practice and the stage of maternal HIV disease. Lastly as this was an observational cohort study HIV results were not blinded to either treating physicians or observers and this may have resulted in some reporting bias.

\section{Conclusion}

This is the first study to report that HIVe children undergoing surgery have a higher risk of developing complications and mortality compared to HIVn children, but a lower risk than that of HIVi children. This should be considered when assessing the risk benefit ratio and age of any surgical procedure.

Acknowledgements and Funding

The funds received from the regional authority of Lombardia were a donation to assist in the care and research of children with HIV and carries no restrictions in study design, collection, analysis, interpretation or publication of data. The funds from the Colleges of Medicine of South Africa are an academic award to the first author to use for any research he 
chooses and caries no limitations in study design, collection, analysis, interpretation or publication of data

\section{Author details}

1Department of Pediatric Surgery, Red Cross War Memorial Children's Hospital, School of Child and Adolescent Health, University of Cape Town, South Africa. ${ }^{2}$ Department of Pediatric Surgery Erasmus MC-Sophia Children's Hospital, Rotterdam, The Netherlands. ${ }^{3}$ Department of Pediatric Medicine, Red Cross War Memorial Children's Hospital, School of Child and Adolescent Health, University of Cape Town, South Africa.

\section{Authors' contributions}

JSK - designed the study, protocol, and case record folders (CRF) as well as performed the analysis. He wrote the draft manuscript and incorporated comments from co-authors. The ethics application and funding applications were submitted by JK as the principal investigator. NvG; GvB- Collected data and data entry as well as follow up of patient data AJWM; HJZ-contributed to the study design, analysis and writing of the manuscript. All authors have read and approved the manuscript.

\section{Competing interests}

The authors declare that they have no competing interests.

Received: 2 November 2010 Accepted: 29 July 2011

Published: 29 July 2011

\section{References}

1. Eley B: Addressing the paediatric HIV epidemic: a perspective from the Western Cape Region of South Africa. Transactions of the Royal Society of Tropical Medicine and Hygiene 2006, 100:19-23.

2. Lallemant M, Jourdain G, Le Coeur S, Mary JY, Ngo-Giang-Huong N, Koetsawang S, Kanshana S, McIntosh K, Thaineua V: Single-dose perinatal nevirapine plus standard zidovudine to prevent mother-to-child transmission of HIV-1 in Thailand. The New England journal of medicine 2004, 351:217-228

3. Geddes R, Knight S, Reid S, Giddy J, Esterhuizen T, Roberts C: Prevention of mother-to-child transmission of HIV programme: low vertical transmission in KwaZulu-Natal, South Africa. South African medical journal = Suid-Afrikaanse tydskrif vir geneeskunde 2008, 98:458-462.

4. Slogrove AL, Cotton MF, Esser MM: Severe infections in HIV-exposed uninfected infants: clinical evidence of immunodeficiency. Journal of tropical pediatrics 2010, 56:75-81.

5. Hygino J, Lima PG, Filho RG, Silva AA, Saramago CS, Andrade RM, Andrade DM, Andrade AF, Brindeiro R, Tanuri A, Bento CA: Altered immunological reactivity in HIV-1-exposed uninfected neonates. Clin Immunol 2008, 127:340-347.

6. Mussi-Pinhata MM, Freimanis L, Yamamoto AY, Korelitz J, Pinto JA, Cruz ML, Losso MH, Read JS: Infectious disease morbidity among young HIV-1exposed but uninfected infants in Latin American and Caribbean countries: the National Institute of Child Health and Human Development International Site Development Initiative Perinatal Study. Pediatrics 2007, 119:e694-704

7. Adhikari M, Kauchali S, Moodley A: Clinical profile and morbidity pattern of infants born to HIV infected mothers in Durban South Africa. Indian pediatrics 2006, 43:804-808.

8. Lin HC, Wang SM, Wu CS, Chang FM, Liu CC: Clinical and immunologic characteristics and therapeutic interventions in children born to human immunodeficiency virus-infected mothers in southern Taiwan. Journal of microbiology, immunology, and infection = Wei mian yu gan ran za zhi 2005, 38:89-95.

9. Bunders MJ, Bekker V, Scherpbier HJ, Boer K, Godfried M, Kuijpers TW: Haematological parameters of HIV-1-uninfected infants born to HIV-1infected mothers. Acta Paediatr 2005, 94:1571-1577.

10. McNally LM, Jeena PM, Gajee K, Thula SA, Sturm AW, Cassol S, Tomkins AM, Coovadia HM, Goldblatt D: Effect of age, polymicrobial disease, and maternal HIV status on treatment response and cause of severe pneumonia in South African children: a prospective descriptive study. Lancet 2007, 369:1440-1451.

11. de Moraes-Pinto Ml, Almeida AC, Kenj G, Filgueiras TE, Tobias W, Santos AM, Carneiro-Sampaio MM, Farhat CK, Milligan PJ, Johnson PM, Hart CA: Placental transfer and maternally acquired neonatal lgG immunity in human immunodeficiency virus infection. J Infect Dis 1996, 173:1077-1084.

12. Kuhn L, Meddows-Taylor S, Gray G, Tiemessen C: Human immunodeficiency virus (HIV)-specific cellular immune responses in newborns exposed to HIV in utero. Clin Infect Dis 2002, 34:267-276.

13. Embree JE, Njenga S, Datta P, Nagelkerke NJ, Ndinya-Achola JO, Mohammed Z, Ramdahin S, Bwayo JJ, Plummer FA: Risk factors for postnatal mother-child transmission of HIV-1. AIDS (London, England) 2000, 14:2535-2541.

14. Patel D, Bland R, Coovadia H, Rollins N, Coutsoudis A, Newell ML: Breastfeeding, HIV status and weights in South African children: a comparison of HIV-exposed and unexposed children. AIDS (London, England) 2009

15. Desai DM, Kuo PC: Perioperative management of special populations: immunocompromised host (cancer, HIV, transplantation). Surg Clin North Am 2005, 85:1267-1282, xi-xii.

16. Owotade FJ, Ogunbodede EO, Sowande OA: HIV/AIDS pandemic and surgical practice in a Nigerian teaching hospital. Trop Doct 2003, 33:228-231.

17. Department of Health: Summary report: National HIV and Syphillis Antenatal Sero-Prevalence Survey in South Africa. Book Summary report: National HIV and Syphillis Antenatal Sero-Prevalence Survey in South Africa (Editor ed.^eds.) City: Directorate Health Systems Research, Research Coordination and Epedimiology Department of Health; 2007.

18. Coovadia $\mathrm{H}$ : Current issues in prevention of mother-to-child transmission of HIV-1. Curr Opin HIV AIDS 2009, 4:319-324

19. Filteau S: The HIV-exposed, uninfected African child. Trop Med Int Health 2009, 14:276-287.

20. Isanaka S, Duggan C, Fawzi WW: Patterns of postnatal growth in HIVinfected and HIV-exposed children. Nutr Rev 2009, 67:343-359.

21. Marinda E, Humphrey JH, lliff PJ, Mutasa K, Nathoo KJ, Piwoz EG, Moulton LH, Salama P, Ward BJ: Child mortality according to maternal and infant HIV status in Zimbabwe. The Pediatric infectious disease journal 2007, 26:519-526.

22. Legrand FA, Nixon DF, Loo CP, Ono E, Chapman JM, Miyamoto M, Diaz RS, Santos AM, Succi RC, Abadi J, et al: Strong HIV-1-specific T cell responses in HIV-1-exposed uninfected infants and neonates revealed after regulatory T cell removal. PLOS ONE 2006, 1:e102.

23. Sutcliffe CG, Scott S, Mugala N, Ndhlovu Z, Monze M, Quinn TC, Cousens S, Griffin DE, Moss WJ: Survival from 9 months of age among HIV-infected and uninfected Zambian children prior to the availability of antiretroviral therapy. Clin Infect Dis 2008, 47:837-844.

24. Heresi GP, Caceres E, Atkins JT, Reuben J, Doyle M: Pneumocystis carinii pneumonia in infants who were exposed to human immunodeficiency virus but were not infected: an exception to the AIDS surveillance case definition. Clin Infect Dis 1997, 25:739-740.

25. Otieno RO, Ouma C, Ong'echa JM, Keller CC, Were T, Waindi EN, Michaels MG, Day RD, Vulule JM, Perkins DJ: Increased severe anemia in HIV-1-exposed and HIV-1-positive infants and children during acute malaria. AIDS (London, England) 2006, 20:275-280.

26. Wei R, Msamanga Gl, Spiegelman D, Hertzmark E, Baylin A, Manji K, Fawzi WW: Association between low birth weight and infant mortality in children born to human immunodeficiency virus 1-infected mothers in Tanzania. The Pediatric infectious disease journal 2004, 23:530-535.

27. Newell ML, Brahmbhatt H, Ghys PD: Child mortality and HIV infection in Africa: a review. AIDS (London, England) 2004, 18(Suppl 2):S27-34.

28. Zaba B, Whitworth J, Marston M, Nakiyingi J, Ruberantwari A, Urassa M, Issingo R, Mwaluko G, Floyd S, Nyondo A, Crampin A: HIV and mortality of mothers and children: evidence from cohort studies in Uganda, Tanzania, and Malawi. Epidemiology 2005, 16:275-280.

29. McHoney M, Eaton S, Pierro A: Metabolic response to surgery in infants and children. Eur J Pediatr Surg 2009, 19:275-285.

\section{Pre-publication history}

The pre-publication history for this paper can be accessed here: http://www.biomedcentral.com/1471-2431/11/69/prepub

doi:10.1186/1471-2431-11-69

Cite this article as: Karpelowsky et al:: Outcome of HIV-exposed uninfected children undergoing surgery. BMC Pediatrics 2011 11:69. 